task-specific influence of similarity on different attraction responses.

\section{REFERENCES}

Byrne, D. The attraction paradigm. New York: Academic Press, 1971.

Byrne, D., \& Clore, G. L. A reinforcement model of evaluative responses. Personality: An International Journal, 1970, 1, 103-128.

Festinger, L. A theory of social comparison processes. Human Relations, 1954, 7, 117-140.

Osgood, C., Suci, G., \& Tannenbaum, P. The measurement of meaning. Urbana, Iilinois: University of Illinois Press, 1957.

Senn, D. Attraction as a function of similarity-dissimilarity in task performance. Journal of Personality \& Social Psychology, 1971, 18, 120-123.

\section{NOTES}

1. An initial four-way between groups analysis of variance indicated that there were no significant effects for the sex of the S.

2. The Ss in the high-certainty (HC) conditions were more sure of their perceptual judgments than Ss in the low-certainty (LC) conditions. This was expressed on the postperceptual task questionnaire in answer to the question "How many of your responses do you feel were correct?" $(\mathrm{HC}=14.47, \mathrm{LC}=11.33$, $\mathrm{F}=13.63$, df $=1 / 63, \mathrm{p}<.001)$.

3. An initial five-way between-within groups analysis of variance indicated that there were no significant effects for the sex of the $S$ and for the certainty manipulation.

(Received for publication February 16, 1974.)

\title{
Cutaneous perception of heroin addicts: Evidence of an altered temporal process*
}

\author{
ROBERT J. HALL and MARJORIE A. ROSENBERGER \\ EG\&G, Inc., Special Projects Division, 3084B South Highland Avenue, Las Vegas, Nevada 89109 \\ and \\ RICHARD A. MONTY† \\ Human Engineering Laboratory, Aberdeen Proving Ground, Maryland 21005
}

\begin{abstract}
The time taken to detect the direction of movement of a stylus drawn across the volar surface of the forearm is greater for heroin addicts than for nonaddicts. The slower the speed of movement of the stylus, the greater the difference. Perception of nontemporally related dimensions is not affected, indicating that the effects of heroin appear to be highly specific, and alter the central nervous system's temporal processes which govern and regulate excitability cycles and cortical scanning.
\end{abstract}

Several recent studies have suggested that there may be fundamental changes in the sensory behavior of drug users and addicts. For example, Smith (1972) reported

* This study was sponsored by the Advanced Research Projects Agency under ARPA Order No. 2128.

tRequests for reprints should be sent to Richard A. Monty, Behavioral Research Directorate, U.S. Army Human Engineering Lab, Aberdeen Proving Ground, Maryland 21005. that the taste thresholds of addicts for quinine were significantly lower than those of controls and alcoholics. Similarly, a recent series of studies of the visual behavior of drug addicts (Hall, Rosenberger, \& Monty, 1973) indicated that there were basic differences between addicts and controls in the rapid eye movement associated with fixation sequences and that these may indicate disturbance of the temporal processes which 


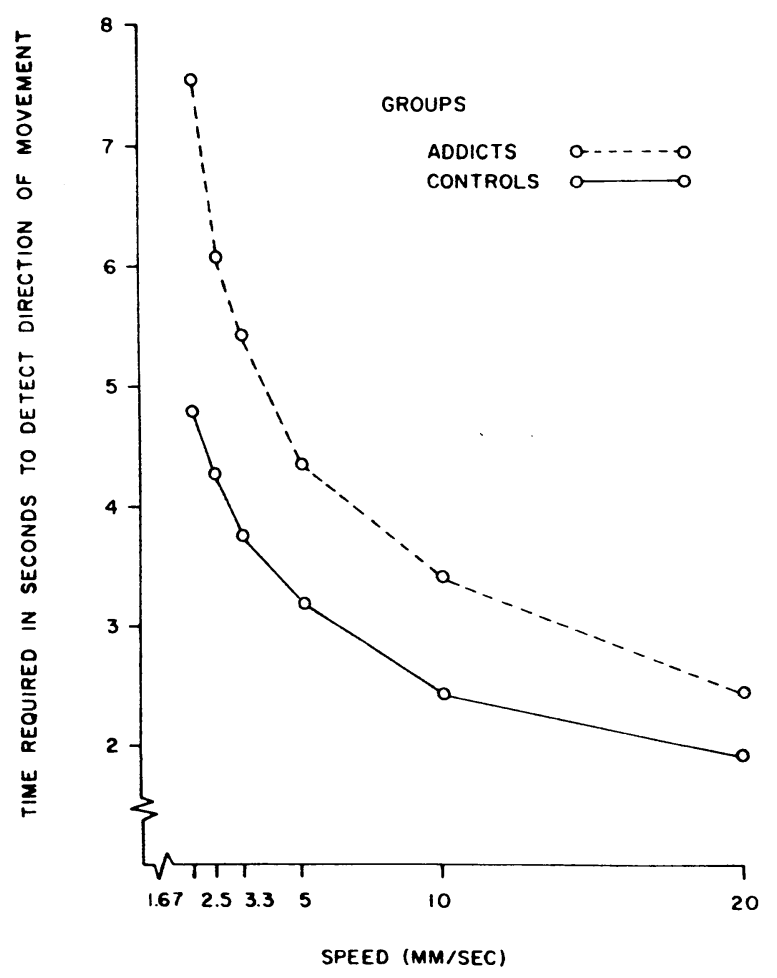

Fig. 1. Time required to detect direction of movement as a function of addiction and speed.

gate and sequence successive fixations. These early studies plus evidence that the neural anatomical correlates of morphine addiction are highly localized (Wei, Loh, \& Way, 1972) suggest that the temporal dimension of heroin addicts' visual processes may be different from those of nonaddicts. Thus, in order to determine the generality of this effect across senses, the present experiment dealt with the effect of rate of movement of a stylus drawn across the volar surface of the forearm, on the perception of that movement, and with differences between heroin addicts and nonaddicts in detecting the direction and movement of the stylus.

\section{METHOD}

\section{Subjects}

The experimental group consisted of 14 male and 14 female heroin addicts drawn from the population of addicts in the Las Vegas area. Heroin addiction was verified by a toxicology screening which used two urine samples taken on different days. In addition, interviews and drug histories were used to determine Ss' addiction and level of toxication. The interviews provided data on the most recent fix and indices of use such as hypodermic tracks, while the drug histories revealed that the addicts were fixing on an average of two to three times per day. A split sample replication of the toxicology screening indicated that the urine analyses performed by an independent laboratory were reliable.

The control group consisted of 14 male and 14 female students from the University of Nevada, Las Vegas of approximately the same age. All Ss were right-handed and screened for any abnormalities or injuries that might interfere with their cutaneous perception of a moving point and all were paid for their participation in the experiment.

\begin{abstract}
Apparatus
The apparatus was designed to trace lines of specified lengths and shapes across the volar surface of the forearm at constant rates and pressures. As the arm rests upon a felt-covered cradle, the point which moves across the cutaneous surface is held in a counterbalanced fulcrum mechanism which produces a constant pressure where the point comes in contact with the cutaneous surface. Depending on the arm being stimulated, $S$ sits comfortably to the left or right of the apparatus which is arranged so that all adjustments and controls manipulated by the $E$ are shielded from view. The S's arm is likewise concealed from view by a box-like hood covering the apparatus and the arm.
\end{abstract}

\section{Procedure}

The Ss were informed that the purpose of the experiment was to determine the direction of movement as rapdily as possible. The $S$ was alerted to the onset of stylus movement, and as soon as he could determine the direction of that movement he pressed a response button and then verbally reported direction. Both the time and accuracy of response were recorded.

The experiment consisted of two sessions which took place on different days. Identical procedures were used in both sessions except that in the first session, half of the Ss were tested with a stylus pressure of $5 \mathrm{~g}$ and the other half with a stylus pressure of $10 \mathrm{~g}$. In the second session, the pressure was just the reverse for all Ss. Each trial started with the stylus resting on the volar surface of the forearm, and the direction of movement (toward the elbow or toward the wrist) and locations of the starting point were randomized and counterbalanced. Each $\mathrm{S}$ received a total of five trials per speed at a stylus point pressure of either 5 or $10 \mathrm{~g}$, for a total of 30 trials per session. The stylus was moved at six speeds: $1.7,2.5,3.3,5.0,10.0$, and $20.0 \mathrm{~mm} / \mathrm{sec}$.

\section{RESULTS}

The principle measure of performance was the time required to detect the direction of movement of the stylus. These scores were subjected to an analysis of variance with sex and addiction (addicted vs nonaddicted) as between effects and pressure and speed as within effects. The data underlying the significant main effect for addiction $F(1,52)=17.55, \mathrm{p}<.001$ indicated that the nonaddicted Ss were consistently faster than addicts, while the data underlying the significant main effect for speed, $F(5,260)=122.27$, $\mathrm{p}<.001$ indicated that in general the faster the speed the better the performance. In addition, the Speed by Addiction interaction reached significance as shown in Fig. 1. It can be seen that the slower the speed the greater the difficulty the addicts had in detecting the direction of movement relative to the controls. It is interesting to note that the standard deviations underlying each of these means were not much larger for addicts (SDs of 4.75, 3.22, 3.03, 2.06, 1.63, and 1.08, respectively) than for the controls (SDs of 3.07, 2.77, $2.12,1.71,1.05$, and 0.69 ).

Pressure also affected speed of detection, $F(1,52)=$ $27.37, p<.001$. Performance was always better for the heavier pressure of $10 \mathrm{~g}$, irrespective of whether the Ss were addicts or controls, and the slower the speed the greater the advantage of the heavy pressure as indicated by the Speed by Pressure interaction, $F(5,260)=4.25$, $\mathrm{p}<.001$. Finally, the Speed by Pressure by Sex 
interaction, $F(5,260)=2.65, p<.05$ also is significant as pictured in Fig. 2. This interaction can be accounted for on the basis that at the slower speeds and lighter pressure females were at somewhat more of a disadvantage than males but that the disadvantage decreased as either speed or pressure increased. There was no evidence that this pattern differed for addicts or controls. For static measures of cutaneous sensitivity such as two point discrimination or point localization, Weinstein (1968) has similarly reported that the forearms of males are more sensitive than females. Recent studies using a moving point on the volar surface of the forearm (Langford, Hall, \& Monty, 1973) have also found sex differences. The important thing to note here is that we have a task that is sensitive to changes in both speed and pressure, yet only speed appears to affect addicts and controls differently, at least within the ranges explored here. Further, differences as a function of speed remain the same for addicts and controls irrespective of sex.

An analysis of errors that occurred when the Ss reported the wrong direction of movement indicated that the average number of errors also decreased as the spesd increased and that the errors for all speeds and stylus pressures were quite low. Specifically, from a total of 60 responses per $S$, the average errors per $S$ for the controls was 11 and for the addicts 8 . Secondly, the differences between the addicts and controls were very small, suggesting that both groups were performing equally well on the task and that the difference between

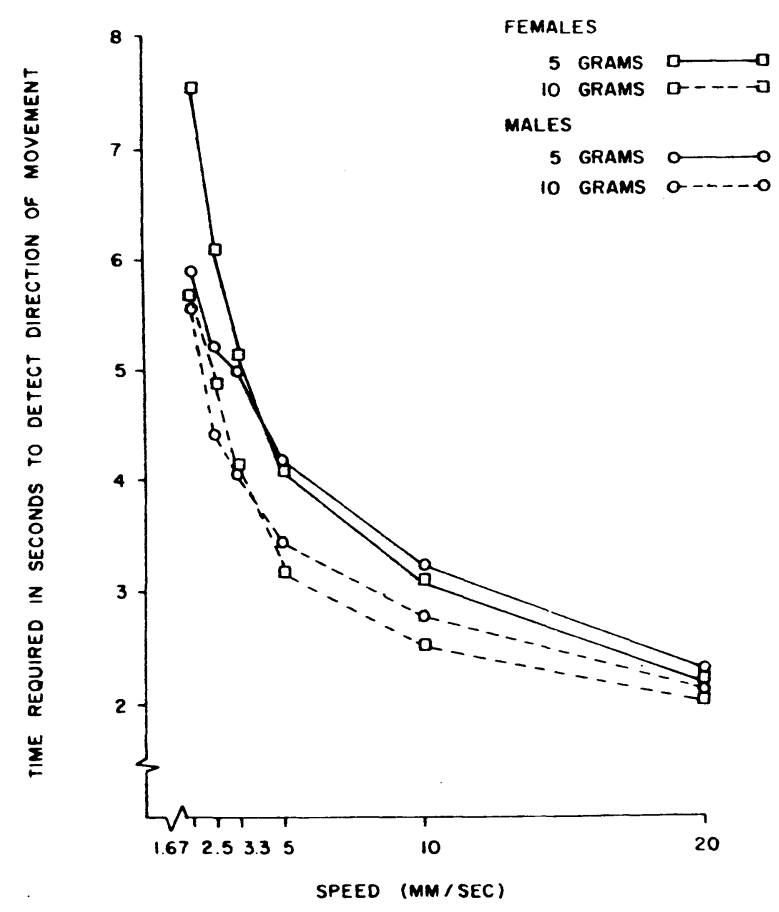

Fig. 2. Time required to detect direction of movement as a function of sex, pressure, and speed. the addicts' and control groups' ability to detect the direction of a moving point on the cutaneous surface is not due to motivational or attitudinal differences. Finally, an analysis of errors as a function of direction was identical for the addicts and control Ss: $54 \%$ of the errors occurred when the stylus was moving toward the wrist and $46 \%$ occurred when the stylus moved away from the wrist irrespective of addiction. These later results suggest that the criterion used by both groups was the same and that the differences in time taken to detect direction of movement are due to some basic differences between the sensory processes of the addict and the control groups.

In summary, the dynamic test of cutaneous sensitivity (S's ability to detect the direction of a moving point on the cutaneous surface) indicated that addicts require more sensory data before they can determine the direction in which the point is moving. A second cutaneous experiment using the same group of addicts and controls, which was concerned with localization of cutaneous tracks on the forearm relative to a reference track, found no difference between the two groups. However, all tracks were produced at the heavier pressure of $10 \mathrm{~g}$ and there were no time constraints to indicate how the amount of available information affects the Ss' responses. Thus, it appears that effects of heroin are highly specific and alter the central nervous system's temporal processes which govern and regulate factors such as excitability cycles and cortical scanning (Harter, 1967). Changes in these gating and timing mechanisms which group incoming sensory data may be responsible for differences between addicts and controls in detecting direction of movement. On the other hand, these changes might not be recognizable as a general effect on more complex tasks such as localization of a cutaneous track. A comparison of the cutaneous data with eye-movement data from an earlier experiment (Hall et al, 1973) suggests that as a group the addicts take longer (longer fixations, greater distance traveled on the skin) to obtain the same sensory information as controls.

\section{REFERENCES}

Hall, R. J., Rosenberger, M. A., \& Monty, R. A. An experimental investigation of the visual behavior of young heroin addicts and matched controls. Technical Memorandum 25-73, U.S. Army Human Engineering Laboratory, Aberdeen Proving Ground, Maryland, 1973.

Harter, M. R. Excitability cycles and cortical scanning: A review of two hypotheses of central intermittency in perception. Psychological Bulletin, 1967, 68, 47-58.

Langford, N., Hall, R. J., \& Monty, R. A. Cutaneous perception of a track produced by moving a point across the skin. Journal of Experimental Psychology, 197 3, 97, 59-63.

Smith, S. E. Taste thresholds in drug addicts and alcoholics. British Journal of Addiction, 1972, 67, 317-321.

Wei, E., Loh, W. W., \& Way, E. L. Neuroanatomical correlates of morphine dependence. Science, 1972, 177, 616-617.

Weinstein, S. Intensive and extensive aspects of tactile sensitivity as a function of body part, sex and laterality. In $D$. R. Kenshalo (Ed.), The skin senses. Springfield, Illinois: Thomas, 1968.

(Received for publication February 4, 1974.) 